\title{
Deep Integration of Al and TPACK: Reconstruction of Teachers' Knowledge Structure in the Post-pandemic Era
}

\author{
Yuan Yao \\ School of Life Science, Shanghai Normal University, Shanghai, China \\ 1000483818@smail.shnu.edu.cn
}

\begin{abstract}
The development of artificial intelligence (Al) technology has brought an unprecedented intelligent reform to teaching, and the COVID-19 pandemic has provided an opportunity for online and offline hybrid teaching mode. During the pandemic prevention and control period, the application of Al technology has brought about subversive changes in teaching methods, teaching content and teaching environment. This is the result of continuous adjustment in teaching practice in schools around the world, and will be a new characterization of teaching practice in the future. The social crisis caused by COVID-19 requires teachers to adjust their knowledge structure accordingly. Based on the new requirements for teachers in the era of AI and the traditional Technological Pedagogical Content Knowledge (TPACK) theory, this paper puts forward a new idea to reconstruct teachers' knowledge structure by deep integration of Al and TPACK. This study studies how teachers should change their knowledge structure from the four dimensions of Pedagogical Content Knowledge (PCK), Technological Content Knowledge (TCK), Technological Pedagogical Knowledge (TPK) and TPACK, and puts forward suggestions for the intelligent development of education, in order to provide new theoretical support for teachers' career development in the Post-pandemic era.
\end{abstract}

Keywords: Artificial Intelligence (Al); Post-pandemic Era; Technological Pedagogical Content Knowledge (TPACK); Teachers' Knowledge Structure.

\section{Research Background}

The COVID-19 pandemic in 2020 has had a huge impact on the traditional education, with significant impacts on both basic and higher education around the world. During the pandemic prevention and control period, countries started online education mode, realizing "suspended classes, continuing teaching and learning". On April 26, 2021, the American association for higher education informatization (EDUCAUSE) officially released the 2021 EDUCAUSE Horizon Report $®$ : Teaching and Learning Edition, saying the pandemic would have a long-term impact on higher education. It has now entered the Post-pandemic era [1]. Online teaching has been adopted by all staff, throughout the whole process and in an all-round way during the pandemic period, forcing teachers and students to improve their informatization skills. People are more open to online education [2], which also promotes the continuous advancement of AI education technology. Online teaching in the Postpandemic era is not only a supplement to offline teaching, but also plays an increasingly important role in higher education and teaching, academic exchanges and teachers' professional growth [3]. Online and offline hybrid teaching has gradually become the norm for education.

In recent years, countries around the world have put forward new requirements on how to correctly use and promote AI education. With the development of AI technology, people have witnessed the most subversive intelligent reform. Different from steam revolution, electrical revolution and information technology revolution, intelligent technology has changed the relationship between technology and human in essence, and will inevitably reshape education and its ecosystem [4]. In July 2017, The State Council of the People's Republic of China issued the Development Plan for a New Generation of Artificial Intelligence (No. 35 Document in 2017 of the State Council), which proposed to use intelligent technology to accelerate the reform of talent training mode and teaching methods, and to build a new education system including intelligent learning and interactive learning. In April 2018, the Ministry of Education of the People's Republic of China issued the Education Informatization 2.0 Action Plan, which is a specific implementation plan to promote "Internet + education". In 2018, the United States released the national AI strategy report A National Machine 
Intelligence Strategy for the United States [5], which clearly proposed that machine intelligence should be combined with teaching. In the Innovating Pedagogy [6] released by the UK Open University in 2019, the concept of "robot companion learning" was put forward for the first time. In May 2019, UNESCO held the first Conference on Artificial Intelligence and Education in Beijing, China, and formed the outcome document "Beijing Consensus - Artificial Intelligence and Education" [7]. All the above shows that the application of AI in the field of education has been highly concerned by countries around the world.

\section{Theoretical Basis}

The earliest theory on teachers' knowledge structure was the Pedagogical Content Knowledge (PCK) theory proposed by Shulman L. S. of Stanford University [8]. This theory describes the knowledge structure that teachers should have, which includes three core elements, namely, Content Knowledge (CK), Pedagogical Knowledge (PK), and Technological Knowledge (TK). The rapid development of information technology makes education inevitably enter the information age. In 2005, Mishra \& Koehler in Michigan State University put forward Technological Pedagogical Content Knowledge (TPACK) [9] based on Shulman's PCK theory. TPACK theory is the development of PCK theory. The three core elements interact with each other to form four composite elements, namely Pedagogical Content Knowledge (PCK) and Technological Content Knowledge (TCK), Technological Pedagogical Knowledge (TPK) and TPACK.

With TPACK theory being put forward for more than ten years, what impact will the rapid development of AI technology have on teachers' knowledge structure? In TPACK theory, technical knowledge is always in a state of change relative to discipline knowledge and teaching knowledge [10], which is the most flexible element in TPACK theory. Therefore, in order to better comply with the requirements of the development of this era and meet the needs of teachers' professional development, AI knowledge and thinking patterns need to be integrated into teachers' knowledge structure. The traditional TPACK theory needs to be endowed with new connotation, and the four composite elements need to be reconstructed accordingly in order to promote teachers to better adapt to the AI era.

\section{Reconstruction of Teachers' Knowledge Structure}

Online education changes the way of human knowledge transmission, and the new design of teaching process, selection of teaching content and arrangement of teaching interaction put forward higher requirements for teachers' knowledge integration ability [7]. Teachers' knowledge structure is a highly organized and systematic structure composed of various types of knowledge, which is the basis of teaching [11]. In the Post-pandemic era, teachers are required to continuously improve their ability to integrate teaching knowledge and information literacy, and promote AI application in teaching. In this era, teachers are supposed to explore and create teaching models and strategies that are more suitable for teacher-student interaction, and use AI technology to assist themselves in making teaching decisions most suitable for students. The Post-pandemic era also requires the reconstruction of teachers' teaching knowledge, integrating soft knowledge, hard knowledge and "dark knowledge" generated by AI [12] [13]. Teachers should adapt to the time and reconstruct the knowledge structure through the deep integration of AI and TPACK.

\subsection{Knowledge Structure Reconstruction based on PCK}

PCK usually refers to the integration of disciplinary knowledge, teaching knowledge and situational knowledge together with its interaction with all three [14], but the connotation of PCK in the era of AI is different from that in the traditional sense. Teachers not only need to transform their knowledge acquired in practice into knowledge that students can acquire, but also need to use AI to create knowledge that is more vivid, individual and situational. Many teachers are still in the state of 
loyal course executor, lack of consciousness of course creation, so that students only passively accept and mechanically memorize knowledge. Teachers should realize that the important goal of education is to help learners build an effective knowledge environment to master the basic skills needed by the knowledge society [15].

In the era of "Internet + education", teachers need to change their roles, master and apply AI to teaching, and become the builders and developers of courses. First, on disciplinary knowledge, teachers should create open knowledge sharing platform. Teachers not only need to constantly update their knowledge structure through the Internet, but also can enrich students' existing knowledge by sharing knowledge with students. Second, on teaching knowledge, teachers should break the one-way mode of knowledge transmission [16] and use AI teaching technology to construct a two-way interaction mode, to present knowledge more vividly. Finally, on situational knowledge, teachers can reconstruct the curriculum to make the knowledge conform to the practical experience of students themselves. From the perspective of overall PCK, teachers need to acquire and recreate knowledge through AI technology and use diversified teaching methods to cultivate students' ability to solve problems based on problem situations.

\subsection{Knowledge Structure Reconstruction based on TCK}

TCK emphasizes the application of technology in disciplinary knowledge, that is, the kind of technology teachers use in class to transfer knowledge to students. Using AI technology can solve some drawbacks of knowledge. First, in the information age, knowledge becomes fragmented. How to systematize knowledge requires teachers to master integration technology and reconstruct the existing TCK knowledge structure assisted by AI technology. Second, AI technology can break the space-time nature of knowledge, and make the present form of knowledge is no longer a single textbook. In particular, open resources for education (ORE) have become more important due to the COVID-19 pandemic. According to a survey, $87 \%$ of teachers said they still used the old textbooks during the pandemic [17]. In the Post-pandemic era, teachers need to use AI technology to flexibly collect, integrate and summarize disciplinary knowledge to increase its breadth and depth. Third, students cannot understand part of the textbook content because of their cognitive limitations. In order to let students, comprehend abstract knowledge, teachers need to use AI technology to enrich the forms of subject knowledge. Through technologies such as intelligent virtual reality [18] that mobilize students' various senses [19], teachers visualize and concretize knowledge to provide students with immersive learning and assist their cognition and thinking [20].

\subsection{Knowledge Structure Reconstruction based on TPK}

TPK emphasizes the application of technology in pedagogy, that is, how teachers use technology to teach students. In traditional offline teaching, teachers mostly know students through daily observation and examination results, and deal with the scores through tables, but they cannot accurately get the scores of each student and each small question. In the era of AI, teachers can analyze students' classroom data, test data and even preview and review data through "students' learning situation analysis" to truly understand students' learning style and provide personalized teaching services for students. Therefore, this requires teachers to reconstruct the knowledge structure of the TPK dimension. Teachers should not just stay in the knowing of AI technology concept without knowing how to make it serve teaching. In order for teachers to master and use AI proficiently, they also need to be able to accurately interpret the student information fed back by AI. For example, the Center for Analysis of Learning and Teaching (C-ALT) of Colorado State University instructs teachers the ability to interpret data [21]. The deep integration of AI and TPK can help teachers to obtain students' learning data more conveniently, assist teachers to adjust teaching activities in time and let teachers design teaching strategies more suitable for students. 


\subsection{Knowledge Structure Reconstruction based on TPACK}

Reconstruction of knowledge structure on TPACK dimension requires teachers to master disciplinary knowledge, pedagogy knowledge and AI technology knowledge at the same time. Specifically, these can be summarized as the following points. First, teachers can use AI technology to present knowledge and concepts that students find difficult to understand. Second, teachers should use AI technology to acquire and integrate more in-depth subject content to broaden students' cognition. Third, AI technology help teachers to achieve intelligent education management and assist teachers to adjust teaching strategies. With the advent of the AI era, teachers use AI for assistance, which is neither an external technical assistance nor letting AI to completely replace teachers, but a technology infiltration with internal integration [22]. The meaning of AI for teachers in TPACK dimension is to use AI technology intelligently under the human-machine collaborative thinking.

\section{Conclusion}

The rapid development of the AI in this era, together with the online teaching propelled by the COVID-19, has led to a huge intelligent revolution in education and its ecosystem. Teaching mode has change from the traditional offline teaching to the online and offline hybrid teaching. Knowledge transmission has changed from one-way transmission mode to two-way interaction mode. Teachers' role has changed from the faithful knowledge imparter to the curriculum builder and developer. These are the practice results of teaching under the continuous adjustment of universities around the world since the outbreak of COVID-19, and will be the new normal of future education, especially higher education. Based on the traditional TPACK theory, this paper puts forward the idea of teachers' knowledge structure reconstruction. In theory, it can provide a new analytical framework for the study of teachers' knowledge structure and help educational researchers to analyze teachers' knowledge structure from a broader, more diversified and more comprehensive perspective. In practice, it is helpful for teachers to understand the new connotation of disciplinary knowledge, pedagogy knowledge and technical knowledge given by AI. At the same time, it provides a new direction for teachers' career development in the Post-pandemic era, helps education managers to better guide teachers' career development, and enables teachers to apply it in teaching practice.

\section{References}

[1] Wang, Z. How Should Education be Transformed in the Post-epidemic Era? E-education Research, 2020, 41 (04): 13-20.

[2] Liu, K., Xing, F., Bao, Z., \& Wu, Y. The Research on Intention of Using Smart Teaching Tools under the Background of "Internet + Education" - A Discussion on the Influences of Novel Coronavirus Epidemic on Blended Education. Higher Education Review, 2020 (1): 181-196.

[3] Zhong, B., \& Nan, X. Overall Reflections on the Development of China's Higher Education in the Postpandemic Era. Educational Research, 2021, 42(05): 108-116.

[4] Liu, C., Wan, P., Wang, Y., \& Yang, G. AI Robots and Instructional Applications: Innovation Implications and Realistic Challenges. Journal of Distance Education, 2020, 38(2): 27-36.

[5] Chen, S., \& He, G. New Exploration of Educational Development and Practice Paradigm from the Perspective of Machine Intelligence: Inspirations on 2018 A National Machine Intelligence Strategy for the United States. Journal of Distance Education, 2018(3): 34-44.

[6] Li, Q., \& Yan, Y. Innovating Pedagogies with Technology: From Playful Learning to Learning with Robots: Introductions to Innovating Pedagogy Report 2019. Journal of Distance Education, 2019(2): 1726.

[7] Zhang, H., Huang, R., Li, J., \& Yin, X. Planning Education in the Artificial Intelligence Era: Lead the Leap--An Interpretation of the Outcome Document of the International Conference on Artificial Intelligence and Education: Beijing Consensus on Artificial Intelligence and Education. Modern Distance Education Research, 2019, 31(03): 3-11. 
Volume 3 (2021)

[8] Shulman, L. Those Who Understand: Knowledge Growth in Teaching[J]. Educational Research, 1986, 15 (2): 4-14.

[9] Koehler, M., \& Mishra, P. What Happens When Teachers Design Educational Technology? The Development of Technological Pedagogical Content Knowledge. Journal of Educational Computing Research, 2005, 32(2): 131-152.

[10] Koehler, M., \& Mishra, P. What is Technological Pedagogical Content Knowledge? Contemporary Issues in Technology and Teacher Education, 2009 (1): 60-70.

[11] Deng, G., Li, Y., \& Zhu, Y. Reconstruction of Teachers' Knowledge Structure Driven by "AI + Education": The Framework of AIPCEK Integrated with Ethics and Its Development Model. Journal of Distance Education, 2021, 39(01): 63-73.

[12] Wang, L. New Concept of Knowledge: Remolding Teaching and Learning in the Age of Intelligence. Journal of East China Normal University (Educational Sciences), 2019, 37(05): 38-55.

[13] Xie, Q., \& Wang, C. "Learning via Application": Tapping into Dark Knowledge to Transform Traditional Modes of Learning in the Age of AI. Modern University Education ,2020(2): 24-31+112.

[14] Park, S., \& Oliver, J. Revisiting the Conceptualisation of Pedagogical Content Knowledge (PCK): PCK as a Conceptual Tool to Understand Teachers as Professionals. Research in Science Education, 2008, 38 (3): 261-284.

[15] Hong, H., Lin, Y., \& Lee, Y. Developing effective knowledge-building environments through constructivist teaching beliefs and technology-integration knowledge a survey of middle-school teachers in northern Taiwan. Learning and Individual Difference, 2019(76):1-9.

[16] Ouyang, J., \& Xu, X. On the inheritance and transcendence of "teaching-academic" communication mode to tradition [J]. Journal of the Chinese Society of Education, 2016(2): 50-55.

[17] Bay View Analytics. Digital texts in the time of COVID: Educational Resources in U.S. higher education, 2020 [EB/OL]. [2021-05-09]. https:// www. Bayview analytics. com/reports/ digital text sin the time of covid.pdf.

[18] Luckin, R., Holmes, W., Griffiths, M., \& Forcier, L. (2016). Intelligence Unleashed: An argument for AI in Education [EB/ OL]. [2021-06-10]. https://www.pearson.com/content/dam/corporate/global/pearsondot-com/files/innovation /Intelligence-Unleashed-Publication.pdf.

[19] Yan, Z., Fu, J., Zhu, Y., \& Duan, Y. AI-Technological Pedagogical Content Knowledge (AI-TPACK): Connotation, Teaching and Learning Practice and Future Issues. Journal of Distance Education, 2020, 38 (05): 23-34.

[20] Quan, G., Gu, X., \& Wu, J. Research on the "Enabling" Effect of Visual Interaction in Artificial Intelligence Education Application. Open Education Research, 2021, 27(04): 111-120.

[21] Center for the Analytics of Learning and Teaching. Who we are and what we do [EB/OL]. [2021-05-09]. https://www.chhs.colostate.edu/alt.

[22] Guo, J., \& Hao, J. Learning Mechanism Under Artificial Intelligence Environment. Modern Distance Education Research, 2019, 31(05): 32-38. 